\title{
National Traditional Sports in College Campus Sports Culture Research ${ }^{1}$
}

\author{
Yan Shen ${ }^{1}$, Liaokun Ye ${ }^{1}$, Sha Zhang ${ }^{2}$, GuiMin $\mathrm{Li}^{2}$ and TaoLin Huang ${ }^{1}$ \\ 1physical Education Department,Kunming University of Science and technology, Kunming 650500, China \\ 2. Yunnan Normal University, Institute of Physical Education, KunMing 650500, China \\ 18288745232@163.com
}

\begin{abstract}
The campus sports culture as an important form of physical form, increasingly emerge in the sports field, this paper, literature, law and logic analysis traceable to the campus sports culture and national traditional sports culture concept, connotation, and mutual integration prospects for analysis of reading, the last draw relevant conclusions and recommendations aimed at traditional sports culture, heritage and development suggestions.

Index Terms - national traditional sports culture on campus
\end{abstract}

\section{Introduction}

Culture is human civilization, is a form of physical or mental state, from a sociological point of view, the existence of sports culture has become a modern society and campus development needs in one sport, sport is not just past simple sports items, and more from simple muscle activity freed, became a form of culture, both ornamental and can participate in both exercise and entertainment, both a sport and a way of education development. Campus sports culture in promoting changes in educational thinking, and promote comprehensive development of students, to adapt to the implementation of the overall quality of education at all levels of education has a unique advantage in the overall quality of education for students with a variety of practical value to the process of "campus sports culture is not only physical fitness, but also for the health of students and the character has a very important role in shaping the "high-grade campus sports culture can be established teachers and sports values, physical attitudes, ideals, beliefs and so on. Campus Sports Culture in cultural exchanges with the outside world is absorbed in the integration of advanced ideas, concepts, and campus culture demonstrated by the various characteristics, and tap the potential of students, and promote the overall development of students, is to enable students from the natural to the community man rotation.

\section{Methods}

A. of literature: the use of network and library resources to find relevant literature to summarize, in order to lay the theoretical foundation writing papers.

B. Traceability law: on the campus sports culture and traditional sports culture formation process and the development of ways to conduct a detailed analysis, the use and development of the law of development of its root causes combined analysis, support for the thesis arguments play a key role.

C. logical analysis: to gather and find literature logical analysis, conclusions of the paper form to provide support.

\section{Results and analysis}

\section{A. Campus Sports Culture and Ethnic Sports Culture} Overview

1) Campus Sports Culture

Campus culture can be defined as: "campus culture is campus space, student, teacher participation in the main, to after-school activities as the main content to culture, multidisciplinary, multi-field extensive exchanges and the unique rhythm of life as the basic form, with characteristics of the times as a group culture; it refers to the campus space, student, teacher participation as the main sports action as a means to a variety of physical exercise as the main content of the project, has a unique manifestation of a kind of group culture from a sociological perspective, the existence of sports culture reflects the people's demand for a social, sporting themselves from mere muscle activity and the state of isolation and culture freed, both sporting and cultural, both exercise and entertainment, both sport and education, both ornamental and can participate in, as a distinct social and cultural phenomenon in modern education and modern sports intersection of these two cultural systems, to generate a unique social and cultural phenomenon - campus sports culture and it is the part of sports culture system, but also the entire system of education and culture a part of sports culture exists an important feature is its nationality and the diversity of people's needs selectivity, ie sports culture does not have a uniform model, but according to the different nationalities, different ages, different genders, different occupations, different sectors and the different stages of social development and people's different needs exist.

Campus Sports Culture is to create a cultural atmosphere and cultural atmosphere of the school is important and indispensable element, is to promote the development of campus culture the most powerful catalysts. Sport is the main carrier of sports and cultural development, not only can play to improve health, and enhance the role of physical fitness, and more importantly, to reflect the fair competition, unity of morality and respect for yourself, respect for others, self-

This work is partially supported :From 2012 Yunnan Education Science Science Planning Project topic (Y12026) support 
improvement, self-confident and aggressive moral character and the mutual exchange, the spirit of mutual cooperation. This is what we should pursue the human spirit. Campus Sports Culture can not only enrich sports knowledge, selfcultivation, propagation healthy way, and can create a healthy, active and lively campus culture to the students to showcase their talents and expertise to build the full platform.

\section{2) Traditional Ethnic Sports Culture}

National Traditional Sports Traditional Sports Culture is an important part, has a unique cultural values, in a sense reflects a nation's traditions and geographical landscape, reflects the history of the nation's light, remains the traditional social production and lifestyle imprint, and ethnic customs, religious worship are inseparable. In recent years, some scholars define the national sport, that "national sports refers to the worldwide spread of modern sports normative activities relative to traditional folk sports" or "national sport is referred to as the predecessor of modern sports some folk traditional sports and entertainment. "National Traditional Sports contains a wealth of cultural connotations, has been deeply affected the survival and development of all ethnic groups, the cultural connotation it is in the minority in the development process derived or created, as the national language, customs , folk and other special skills, like a certain heritage and national identity, and national sports with human generation to grow together, so they are closely linked; minority traditional sports are not always there, and is essential for the survival of its people and in labor productivity gradually produced; national traditional sports has its unique culture, represents a different course of development of the nation's production and history.

\section{B. National Traditional Sports Culture and Campus Culture Difference Analysis}

1) conceptual differences. Campus Sports Culture is happening in schools within the scope of sports-related cultural phenomenon, refers to the school staff, students have taken the sporting spirit, practice mode and create a spirit of sport and physical outcomes sum;-called traditional ethnic Sports is our various ethnic people in the long-term production, life and military combat practice, gradual accumulation, with Chinese traditional features, including martial arts and other projects as the basic content of a variety of health, fitness and entertainment, a variety of a variety of sports activities;

2) different social. Campus Sports Culture is the development of a school sports, are sports spiritual tradition and carry forward. Whether or spiritual from the material level perspective, the construction of campus sports culture will undoubtedly make the development of school sports to a higher level, while the traditional sports culture is a national cultural heritage and inheritance, to promote personal and individual, personal and national, ethnic and inter-ethnic harmony blending, harmonious whole positive impact;
3) the economic value varies. Enhance the development of the campus sports culture is rich in its material form, including the school's sports equipment, venues, facilities and other construction improve and enhance the development of the sports industry, and national sports culture led national sports industry development, promoting national DSAs industrial and economic growth, promote national unity, for the traditional culture of ethnic areas of sports development has played a crucial role.

\section{Campus Sports Culture and National Traditional Sports Culture fusion analysis}

Malinowski said: "The cultural traditions must be passed from one generation to the next generation, some kind of educational methods and mechanisms must exist in every culture." Therefore, the campus is to carry forward the traditional national sports culture the best place, the campus sports culture on campus is already forming, the road needs to continue to develop new elements are added in order to have more room for development, traditional sports campus at this time element is sports and cultural development is most needed fresh blood, combined with local resource advantages, the development of national sports culture into the campus sports culture, for example: national aerobics, traditional martial arts, folk dances, etc., not only can ease the pressure of study, widely friends, spend time, physical fitness, but also will enhance the knowledge of more traditional sports culture from the campus this communication platform to flourish and become the school's sports culture.

\section{Conclusions and recommendations}

\section{A. Conclusion}

Campus Sports Culture is a substance, system, the sum of spiritual culture, its values are the core of sports culture, whether it is on campus sports equipment, or sporting events billboards or is it sports competitions are campus sports culture transmission, has been since the campus sports culture and social environment are closely related to each other, making the campus sports and cultural heritage is no longer a simple matter and institutional level to pass, but the spirit of the passing the torch, along with the development of traditional sports, campus sports culture their integration and common development will be the future development of the campus sports culture an important channel.

\section{B. recommends}

1) Schools intensify support to make the campus sports culture that encourages students to participate in extracurricular physical exercise the main way, it is the students understand the main platform for sports information;

2) promote geographical advantage resource projects, so that the traditional advantages of the project to enter the campus sports sports cultural interaction range, and ultimately enable students to understand and learn more traditional sports items; 
3) The right to establish students' conceptual understanding of the campus sports culture so that students from the ideological construction of the campus sports culture generates attention;

4) vigorously publicize and implement the National Traditional Sports Culture and Campus Sports Culture of combining measures to enrich the campus sports culture and content;

5) together with nearby universities campus sports culture festival organized to make the campus sports culture between the schools is more intense, as campus sports culture lay the foundation for long-term development.

\section{References}

[1] Gu Mingyuan. Education Dictionary (Volume 3). Shanghai: Shanghai Education Press, 1991 (7)

[2] Yi Jiandong of Sports Culture. Beijing: Beijing Sports University University Press, 2006: 156-169

[3] Nnian, Cheng Yishan, China Cultural Debates [M]. Beijing: China Renmin University Press, 2006

[4] Stratification and Mass Liude Pei. Sports sociology [M]. People's Sports Publishing House, 2007,9

[5] Yi Jiandong of Sports Culture. Beijing: Beijing Sports University University Press, 2006: 12

[6] Wang Aihua. On the Construction of Campus Sports Culture Environment. Beijing Sport University, 2007, 27 (9): 1260-1261 